\title{
Educar em tempos de incertezas: a implementação do ensino remoto na rede municipal de Floriano-Piauí
}

\author{
Education in uncertain times: the implementation of remote education in \\ the Municipal Department of Education of the city of Floriano -Piauí
}

\author{
Andreia Martins \\ Doutorado em Educação \\ Universidade Federal do Piauí - UFPI. \\ Floriano, Piauí - Brasil. \\ andreiamartins.ufpi@gmail.com
}

Ágata Laisa Laremberg Alves Cavalcanti

Doutorado em Educação

Universidade Federal do Piauí - UFPI.

Floriano, Piauí - Brasil.

agatalaysa@ufpi.com.br

Anne Caroline Soares Dourado

Mestre em Educação

Universidade Federal do Piauí - UFPI.

Floriano, Piauí - Brasil.

acsdourado@ufpi.edu.br

Resumo: A Pandemia da COVID-19 provocou profundas mudanças no contexto educacional do Brasil a partir da instauração do surto da doença e das orientações para a contenção do vírus através do isolamento social. Nesse estudo, partimos da seguinte questão norteadora: como ocorreu o planejamento e quais ferramentas foram usadas para a implementação do Ensino Remoto pela SME de Floriano-PI? O artigo tem como objetivo apresentar e analisar os documentos produzidos pela Secretaria Municipal de Educação (SME) de Floriano-PI para o enfrentamento da Pandemia da COVID-19 nas escolas de Educação Infantil e Ensino Fundamental. O trabalho se insere no campo da História do Tempo Presente, utilizando como fonte documental decretos, circulares, textos e normativas produzidos pela SME de Floriano para regulamentar as aulas não presenciais.

Palavras-chave: Ensino remoto. Educação. Floriano-Piauí. Tecnologias.

Abstract: The COVID-19 Pandemic has caused significant changes in the Brazilian educational context, as of the disease outbreak and the guidelines for containing the virus through social isolation. This study stems from the following guiding question: how did planning take place and which tools were used for the implementation of Remote Education by the Municipal Secretariat for Education (MSE) of Floriano-PI? This article aims to present and analyze the documents produced by the MSE of Floriano-PI in order to cope with the COVID-19 Pandemic in Early Childhood and Elementary Schools. This work is in the field of History of the Present, and decrees, information bulletins, texts and norms produced by Floriano's MSE were used as a documentary source to regulate non-classroom classes.

Keyword: Remote education. Education. Floriano-Piauí. Technologies. 
MARTINS, Andreia; CAVALCANTI, Ágata Laisa Laremberg Alves; DOURADo, Anne Caroline Soares. Educar em tempos de incertezas: a implementação do ensino remoto na rede municipal de Floriano-Piauí

\section{Tecendo a história do tempo presente...}

Em março de 2020 fomos surpreendidos com a suspensão das aulas em todos os níveis da educação no Estado do Piauí. Essa situação ocorreu devido à pandemia mundial do novo coronavírus, também denominado de COVID-19. A Universidade Federal do Piauí, em 16 de março, publicou uma nota comunicando a suspensão das aulas presenciais a partir de 17 de março até 15 de abril. Naquele momento, tudo era muito incerto e sequer se imaginava que não haveria mais aulas presenciais na universidade ao longo de todo o ano de 2020 devido ao aumento do número de infectados e mortes pelo vírus no Brasil e no Estado do Piauí.

O governo do Estado do Piauí lançou o Decreto 18.884 em 16 de março de 2020, que regulamentou as medidas de emergência de saúde pública no Estado. No Art. 10 foi determinada a suspensão das aulas por 15 dias nas redes públicas e particulares. O município de Floriano-PI, objeto de nosso estudo, em 16 de março publicou o Decreto n. 32, que regulamentou as medidas temporárias a serem adotadas no âmbito do município para a prevenção e o enfrentamento da emergência de saúde pública decorrente do novo coronavírus - COVID-19.

O município de Floriano está localizado a 247 quilômetros da cidade de Teresina, capital do estado do Piauí. É uma cidade que possui uma população estimada em torno de 60.025 pessoas, com uma porcentagem de crianças matriculadas na escola de 98,1\% nas idades de 6 a 14 anos. Segundo o Instituto Brasileiro de Geografia e Estatística ${ }^{1}$ (IBGE), o Índice de Desenvolvimento da Educação Básica de 2017 apresentava uma nota de 5,5 para os anos iniciais do Ensino Fundamental na rede pública e 4,7 nos anos finais dessa mesma etapa. Em 2018, o número de matrículas totalizava 8.086 no Ensino Fundamental com 543 docentes ativos, segundo os dados do mesmo instituto.

A questão norteadora de nossa investigação é a busca do entendimento de como ocorreu o planejamento e quais ferramentas foram usadas para a implementação do Ensino Remoto pela Secretaria Municipal de Educação (SME) de Floriano. A partir disso, tem como objetivo apresentar e analisar os documentos produzidos pela SME de Floriano-PI para o enfrentamento da Pandemia do COVID 19 nas escolas de Educação Infantil e Ensino Fundamental.

O trabalho encontra-se no campo da História do Tempo Presente. Buscar construir uma História do Tempo Presente é sempre complexo, pois, quando pensamos em fazer história, geralmente pensamos em algo do passado. Peter Burke (1992), em seu livro A escrita da história: novas perspectivas, nos informa que a função da história é ordenar informações do passado. Para Hobsbawm (1995) o historiador tem como função lembrar a sociedade daquilo que ela teima em esquecer. Então o que é fazer a História do Tempo Presente? Ao buscarmos entender como está 
MARTINS, Andreia; CAVALCANTI, Ágata Laisa Laremberg Alves; DOURADo, Anne Caroline Soares. Educar em tempos de incertezas: a implementação do ensino remoto na rede municipal de Floriano-Piauí

ocorrendo a implementação e o desenvolvimento do Ensino Remoto na rede municipal de Floriano, procuramos tecer uma história que ainda está acontecendo, uma tentativa inicial de pensar historicamente esse processo que está em andamento ao longo do ano de 2020. Em educação trabalhamos com um conceito de cultura escolar, entendida como:

[...] um conjunto de normas que definem conhecimentos a ensinar e condutas a inculcar, e um conjunto de práticas que permitem a transmissão desses conhecimentos e a incorporação desses comportamentos; normas e práticas coordenadas a finalidades que podem variar segundo as épocas (finalidades religiosas, sociopolíticas ou simplesmente de socialização) (JULIA, 2012, p. 10).

Ao pensarmos a educação escolar, logo pensamos em um espaço, um prédio, chamado de escola, com salas de aula, carteiras enfileiradas, quadro, mesa, alunos e alunas, professores e professoras, todos no mesmo ambiente. Há um planejamento de aula, organizado em um calendário escolar, com conteúdo, avaliações, com todas as pessoas juntas e nossa cultura escolar parte do princípio de pessoas reunidas para que aconteça o processo educativo. Com a pandemia e a suspensão das aulas a partir do mês de março de 2020, tivemos que repensar nosso conceito de escola, de educação, de aula, de ensino, portanto.

As primeiras normativas governamentais propunham um Ensino Remoto mediado por tecnologias digitais. Essa proposta, que surgiu para que as escolas enfrentassem a pandemia, acarretou uma mudança repentina em nossa forma de conceber a educação, em nossa cultura escolar secular que se baseava, historicamente, na reunião de crianças em instituições escolares. Como poderemos, agora, ministrar uma aula com cada um em sua casa? Como se dará o processo de ensino e aprendizagem? Essas foram as indagações iniciais de professores, gestores e discentes. Quando foi proposto o ensino remoto, o primeiro entendimento era de que vivíamos uma emergência sanitária e, como profissionais da educação, fazia-se necessário rever/repensar nossa forma de ensinar e aprender, para que as crianças, mesmo em casa, se mantivessem ligadas aos conhecimentos escolares.

Inicialmente, se entendeu que o ensino remoto era mediado por tecnologias digitais, plataformas e ferramentas. Mas, logo nos deparamos com problemas estruturais, como: falta de acesso à internet e ausência de computadores e celulares adequados, tanto por parte dos docentes como dos discentes. Para além das dificuldades em relação ao acesso à internet, aos computadores, aos tabletes e aos celulares, nos deparamos com discentes e docentes que não sabiam como acessar as plataformas nos processos de ensino e aprendizagem. Entendeu-se que não bastava às políticas públicas lançarem decretos e portarias regulamentando o Ensino Remoto, teria que haver uma viabilização para que isto se efetivasse. 
Os riscos de se fazer a história do tempo presente é que ela está em processo, ou seja, escrevemos no caminhar. É importante o entendimento do provisório, pois o pesquisador encontra-se inserido de forma direta no objeto pesquisado, tudo encontra-se em construção e a “[...] história do tempo presente é feita de moradas provisórias" (BÉDARIDA, 2002, p.221).

\footnotetext{
Assim, a noção de história do tempo presente está associada à ideia de um conhecimento provisório que sofre alterações ao longo do tempo. Isso significa dizer que ela se reescreve constantemente, utilizando-se do mesmo material, mediante acréscimos, revisões e correções. Outra singularidade do tempo presente é a valorização do evento, da contingência e da aceleração da história (DELGADO, FERREIRA, 2013, p. 23).
}

Ao buscarmos historicizar como ocorreu o enfrentamento da pandemia da COVID 19 em Floriano-PI, a inserimos em um contexto nacional e mundial. A ideia é compreender o tempo presente, contrapondo-o com o passado, entendendo que a cultura escolar não é estática e o que acontece na sociedade tem relação direta com a instituição escola. Logo, a pandemia fez rever o nosso fazer docente, encontrar alternativas de ensino para enfrentar este momento histórico e isso se constitui no trabalho do educador do tempo presente.

Serão usados como fonte documental os textos construídos pela Secretaria Municipal de Educação de Floriano para o Ensino Remoto. São eles: - Plano Emergencial de Orientações Pedagógicas Para o Ensino Não Presencial na Rede de Educação de Floriano/Piauí; - Cronograma - Período de Execução do Plano; - Projeto Para Implementação de Atividades Não Presenciais na Modalidade de Educação de Jovens e Adultos (EJA) Durante a Pandemia de COVID-19; Projeto Para Implementação de Atividades Não Presenciais na Modalidade de Educação Especial na perspectiva Inclusiva Durante a Pandemia de COVID-19; Relatório de Acompanhamento das Atividades Pedagógicas no Período de 15 de Junho a 31 de Julho.

Vivemos em um mundo em constantes mudanças, isto é, não é possível permanências e, no tempo presente, nada é feito para durar. Conforme Bauman (2003) conceituou, esse tempo é tido como Modernidade Líquida, no qual as relações sociais, econômicas e de consumo, são perpassadas por um modismo, são fugazes, são maleáveis como os líquidos, não há forma. Tudo está em constante mudança e não podemos falar que estamos em uma crise, pois as crises na educação são permanentes, talvez até um projeto político, provocando nos professores inseguranças contínuas. Nesse cenário, o Ensino Remoto tornou-se mais um desafio, que os docentes precisaram enfrentar, se reinventando e formando-se no processo.

No início do ano de 2020, a SME de Floriano realizou seu planejamento junto ao Conselho Municipal de Educação. Os docentes retornaram das férias no dia 17 de fevereiro, iniciando o período de planejamento, que é chamado de Jornada Acadêmica, que terminou no dia 28 do 
referido mês. Após o tempo dedicado ao planejamento do ano letivo, as aulas em todas as escolas do município iniciaram no dia 02 de março. Exatos 15 dias após o início das aulas presenciais, veio a paralização devido à pandemia da COVID-19.

Para Morin (2003), enfrentar as incertezas é um postulado básico para a existência humana. Isso não significa que não devemos nos organizarmos, nos planejarmos. É importante termos um programa de ensino, mas é fundamental pensarmos nas estratégias de como iremos agir caso esse programa não possa ser efetivado como planejamos. No momento em que veio a pandemia, a equipe gestora da educação de Floriano-PI precisou repensar seu planejamento, uma vez que suas certezas se desfizeram.

\section{O que dizem os documentos...}

Diante do cenário apresentado, a SME de Floriano-PI elaborou um Plano emergencial de orientações pedagógicas para o ensino não presencial na rede municipal de educação da cidade, estabelecendo os fundamentos e os encaminhamentos para a realização de atividades não presenciais, delineando acerca do planejamento, dos conteúdos, dos procedimentos e recursos de mediação e do cronograma das atividades propostas, além da avaliação da aprendizagem.

As ações estabelecidas no cronograma perpassam desde o planejamento das atividades para o ensino não presencial até o período da execução. Foi destacada no referido documento a importância da formação para os usos dos recursos tecnológicos com toda a equipe da escola, de modo especial da Plataforma digital Google classroom .

Os fundamentos das atividades não presenciais foram pautados nos Decretos estaduais e municipal, bem como na necessidade de manutenção da continuidade das atividades escolares não presenciais, articuladas através da utilização das ferramentas tecnológicas. O ensino remoto surge, portanto, " [...] na tentativa de nomear as ações pedagógicas criadas para atender às regulamentações emergenciais emitidas pelos órgãos públicos no que se refere à educação escolar em tempos de pandemia” (SANTANA; BORGES, 2020, p.81). Nesse contexto, para a elaboração do Plano emergencial, a Secretaria de Educação considerou um diagnóstico realizado com o levantamento do número de estudantes que realizaram atividades não presenciais no período de férias coletivas e que intensifica as ações conjuntas, desenvolvidas no Ensino Fundamental Anos Iniciais e Finais, da Educação de Jovens e Adultos, da Educação do Campo. Ancora-se, ainda, na Art.32 da Lei de Diretrizes e Bases da Educação (9.394/1996), que delineia acerca do Ensino fundamental a ser realizado de forma a distância como complementação da aprendizagem em situações emergenciais (BRASIL, 1996). 
Em relação ao planejamento, o Plano orientou a utilização as estratégias tecnológicas para o ensino virtual, que deverão ser informadas previamente aos estudantes. Os horários das aulas e a carga horária foram definidos conforme cronograma estabelecido entre as instituições de ensino. Coube às escolas e aos seus gestores, aos coordenadores pedagógicos e aos professores incentivar os alunos a desenvolver uma rotina de estudos e articularem as ações referente aos direitos de aprendizagem dos alunos, de modo a viabilizar a devolutiva das atividades.

Os conteúdos foram elaborados conforme os componentes curriculares de cada área do conhecimento, utilizando materiais de apoio, tais como textos em PDF, páginas dos livros, links, etc. Na elaboração do planejamento de ensino, as escolas devem assumir o compromisso para organizarem e sistematizarem as aulas para proporcionar uma melhor distribuição da carga horária por componente curricular. Para os anos iniciais do Ensino Fundamental, o plano dispõe que os componentes curriculares sejam estudados através da interdisciplinaridade, excetuando as áreas de língua portuguesa e matemática.

Acerca dos recursos didáticos utilizados no processo de mediação pedagógica, devem ser escolhidos de forma a considerar a realidade e o contexto em que cada aluno vive para atender as necessidades deles. O Plano orienta a utilização de atividades virtuais e atividades impressas. As atividades virtuais envolvem a utilização das mídias digitais, plataformas virtuais e as redes sociais, a destacar: Whatsapp, Google classroom, Facebook e Instagram. Além da utilização do livro didático, as atividades impressas, como cadernos de atividades impressas, elaborados de acordo com os componentes curriculares, estão sendo utilizadas no âmbito do ensino remoto na cidade de Floriano-PI.

Pretto, Bonilla e Sena (2020) destacam que as empresas, tais como Google, Facebook e Microsoft ampliaram suas possibilidades, desenvolvendo novos recursos gratuitos, que passaram a ser utilizados nos sistemas educacionais para que a educação continue em tempos de Pandemia. Em contrapartida, também acentua as desigualdades sociais que o ensino remoto traz, principalmente no que tange ao uso das tecnologias e do trabalho em bome office. Nesse sentido, em muitos lares, há dois, três, quatro ou até mais crianças em idade escolar e a disponibilidade de recursos tecnológicos na casa, na grande maioria, é limitada (um celular para gerenciar as atividades escolares e de trabalho de todos na casa). Essa também é realidade presente no município de Floriano-PI, que enfrenta, também, as limitações quanto o acesso à internet. Por isso, a utilização de materiais e atividade impressos é predominante na cidade.

Os professores da Educação infantil e dos anos iniciais do Ensino Fundamental estão utilizando atividades impressas e disponibilizando atividades lúdicas e de orientação de estudos 
através do Whats App. Nos anos finais do Ensino Fundamental, os professores já passam a utilizar a plataforma Google classroom e também, o WhatsApp. Moran (2003, p.5) afirma que “[...] estamos aprendendo a desenvolver propostas pedagógicas diferentes para situações de aprendizagem diferentes".

Educar em ambientes virtuais exige mais dedicação do professor, mais apoio de uma equipe técnico-pedagógica, mais tempo de preparação - ao menos nesta primeira fase, e principalmente de acompanhamento, mas para os alunos há um ganho grande de personalização da aprendizagem, de adaptação ao seu ritmo de vida, principalmente na fase adulta (MORAN, 2003, p.10).

Apesar das orientações propostas pelo plano, há um cenário de incertezas que exige que a comunidade escolar se reinvente, abra possibilidades para o novo, em que as tecnologias podem construir significativamente para os processos de ensino e aprendizagem. Portanto, “[...] cabe ás escolas definirem a forma de devolutiva das atividades pedagógicas não presenciais pelos estudantes durante o período de pandemia, podendo estas serem postadas em ambiente virtual e/ou entregues no retorno das aulas presenciais" (FLORIANO, 2020b, p.6).

Compreendemos que esse é um desafio para os profissionais da educação, desde os gestores, coordenadores pedagógicos e professores, que enfrentam as constantes dificuldades para se adaptarem e manterem a qualidade do ensino. Como destaca Nóvoa (2020), os sistemas educacionais não estavam preparados para essa crise, aliás nenhum setor estava. Mas, apesar das dificuldades enfrentadas, é preciso que os sistemas educacionais atuem no sentido de fortalecer a educação, de não acentuar as desigualdades sociais, mas de possibilitar estratégias que as minimizem. Desse modo, a articulação entre as escolas e a família é essencial para a permanência do aluno na escola de forma a evitar a evasão.

No que diz respeito à avaliação da aprendizagem, ela constitui um desafio ainda maior. Como realizar uma avaliação que considere o desenvolvimento da aprendizagem do aluno quando ele está em espaços distintos do professor? Quais ferramentas avaliativas são necessárias para a avaliação do aluno no ensino remoto? A complexidade do processo avaliativo demanda que os profissionais repensem a avaliação como um processo contínuo, que supere a visão apenas de uma avaliação formativa e meramente qualitativa. Esse contexto de Pandemia exige constantes mudanças e a educação também precisa se reestruturar nesse cenário. Repensando a forma como ensinamos e também como avaliamos no tempo presente.

O Plano emergencial define que é preciso realizar esse processo avaliativo, respeitando as especificidades dos alunos no período emergencial de aulas não presenciais. Por isso, os professores precisam definir que ferramentas avaliativas irão utilizar nesse processo, e quais critérios serão utilizados nessa avaliação, a considerar: 
[...] o acompanhamento através de instrumentais (elaboração de fichas de entrega/recebimento, data de acessos, fotografias, entre outros), da participação e a assiduidade dos estudantes durante a realização das atividades, sejam em plataformas virtuais ou em materiais impressos, que deverão ser arquivados na escola, pois as atividades que os compõem devem ser consideradas para os registros da frequência escolar dos estudantes. (FLORIANO, 2020b, p.6)

Todas as atividades realizadas devem ser registradas no diário de classe de acordo com o horário das aulas presenciais e a carga horária de cada componente curricular. Sendo considerada a falta justificada nos casos em que o aluno não participe das aulas. O Plano prevê para um retorno de aulas presenciais a realização de uma avaliação diagnóstica (FLORIANO, 2020b). Mas, entendemos que ainda é distante esse contexto. Por ora, se faz preciso pensar no tempo presente, nas mudanças necessárias para a viabilização do ensino remoto, para manter a qualidade de minimizar a evasão dos alunos da escola.

Para além das orientações previstas no Plano emergencial de educação, precisamos refletir acerca do papel da escola e do reducionismo da educação, do trabalho do professor e de um ensino que se materializa apenas na realização de atividades (PRETTO; BONILLA; SENA, 2020). Isso deve ser feito com o intuito de que o ensino remoto não se torne algo mecânico, mas que priorize o desenvolvimento da aprendizagem do aluno de forma significativa, através da mediação pedagógica entre professor-aluno-conteúdo, para a realização de atividades que estimulem a formação de cidadãos críticos, reflexivos, criativos e emancipados.

A SEMED dispõe, ainda, como parte de seu plano de ação para as atividades de ensino durante a pandemia, um Projeto para implementação de atividades não presenciais específico para a modalidade de Educação de Jovens e Adultos (EJA). Considerando o potencial inclusivo e compensatório dessa modalidade, a Prefeitura de Floriano oferta turmas no período da tarde e da noite, contemplando alunos da zona urbana e do campo, totalizando 26 escolas.

O projeto define que a EJA utilizará as mesmas ferramentas do Plano Geral já mencionado, como: o Google classroom, WhatsApp, Instagram, Facebook, livro didático e as atividades impressas. Estas atividades foram organizadas tendo em vista a diversidade de alunos da EJA, na qual pode-se observar adolescentes, alunos trabalhadores e idosos. Sob essa perspectiva, o projeto define que:

As turmas diurnas da sede que comtemplam 4a e 5a etapas utilizarão a plataforma Google classroom assim como o livro didático, pois acredita-se que os mesmos por se tratarem de adolescentes apresentem um maior conhecimento e domínio das ferramentas digitais. Em se tratando da EJA no campo, os mesmos utilizarão as atividades impressas em virtude da falta de acesso à internet e as ferramentas digitais, assim como o ensino noturno que comtemplam da 1a a 5a etapa (FLORIANO, 2020c, p.03). 
Observa-se que os alunos diurnos da $4^{\mathrm{a}}$ e $5^{\mathrm{a}}$ da zona urbana são adolescentes com acesso à internet, em contraponto aos alunos diurnos do campo que são, em maioria, adultos sem acesso à internet. Outras características são apresentadas pelos alunos do turno da noite, composto, principalmente por alunos trabalhadores, realidade que o projeto utiliza para justificar a redução na quantidade de atividades.

Em relação ao quantitativo das atividades relacionadas as turmas de EJA 1a, 2a , 3a , $4^{\mathrm{a}}$ e $5^{a}$ etapas que funcionam no turno da noite, serão feitas reduções na quantidade de atividades referentes a cada componente curricular tendo em vista que uma grande quantidade de atividades a serem respondidas a distância sem a presença do professor [...] por se tratarem de pessoas que trabalham durante o dia tendo somente a noite para se dedicarem aos estudos (FLORIANO, 2020c, p.03)

No sentido de operacionalização da atividade, o Projeto descreve que os docentes devem enviar de, maneira on-line ou fisicamente, as atividades para os gestores que ficam encarregados de imprimir e distribuir aos alunos quinzenalmente. No intuito de evitar o contágio do Covid19 durante a entrega ou recebimento das atividades impressas duas medidas básica são tomadas:

Em relação a entrega das atividades, caberá aos gestores, coordenadores ou responsáveis pelas escolas providenciar a impressão e a distribuição das mesmas, encarregando-se de tomar todos os cuidados para evitar aglomerações e seguir as orientações das autoridades sanitárias, [...] As atividades entregues pelos alunos permanecerão na escola e deverão serem corrigidas somente no retorno das aulas presenciais (FLORIANO, 2020c, p.04).

Os gestores devem arquivar todos os planos e as atividades com o objetivo de organizar um futuro portfólio individual que servirá para registrar a frequência dos alunos e, ainda, contabilizar a carga horária do ano letivo. Quanto às avaliações, ficou definido que elas serão aplicadas apenas no retorno das atividades presenciais, cujo intuito é não causar prejuízo ao desempenho avaliativo individual dos alunos.

Além de um Projeto específico para a Educação de Jovens e Adultos a SEMED apresentou, ainda, um Projeto para a Educação Especial na perspectiva inclusiva. Tal documento dispõe de objetivos e estratégias para a execução do Plano geral do município, considerando as especificidades dos alunos da Educação especial.

Esse pressuposto é compartilhado pela Campanha Nacional pelo Direito à Educação, que, em seu Volume 7 do Guia COVID19, aponta para as diferentes barreiras presentes nos meios físicos e de comunicação que podem comprometer a participação dos estudantes da educação especial nas estratégias adotadas pelas redes nas práticas de ensino remoto. A Educação Especial é uma modalidade de ensino e está presente em todas as etapas e níveis de ensino, sendo também concomitante às outras modalidades. Logo, é preciso considerar a sua existência e propor 
MARTINS, Andreia; CAVALCANTI, Ágata Laisa Laremberg Alves; DOURADO, Anne Caroline Soares. Educar em tempos de incertezas: a implementação do ensino remoto na rede municipal de Floriano-Piauí

mecanismos que proporcionem o acesso e a permanência dos alunos nas atividades escolares (GUIA COVID, 2020).

Segundo o Plano para a Educação Especial (FLORIANO, 2020d), o objetivo de se traçar estratégias específicas da Educação Especial consiste em conservar o vínculo do aluno, públicoalvo da educação especial com a escola durante o período de ausência de aulas presenciais. Além disso, propõe a orientação da equipe multidisciplinar, profissionais do Apoio Educacional Especializado (AEE), interpretes e cuidadores educacionais, especificando a maneira de proceder nos acompanhamentos dos alunos com algum tipo de dificuldade nas atividades remotas no período de pandemia.

Nesse sentido, as estratégias consistem na realização de planejamentos pedagógicos frequentes, entre professores, gestores e equipe de AEE. Os professores responsáveis pelas turmas devem fazer as atividades e caberá ao profissional do AEE adequá-las aos alunos e orientar as famílias na resolução de tais tarefas.

\footnotetext{
Quinzenalmente serão realizados planejamentos pedagógicos com os profissionais que hora acompanham os alunos da educação especial; Os professores de AEE farão as adequações das atividades pedagógicas orientados pelos professores regente de sala, em como orientarão as famílias (FLORIANO, 2020d, p.04).
}

No tocante aos alunos surdos, a prefeitura disponibiliza Interpretes - profissionais que são mencionados no plano como um contato diário dos alunos surdos - cujas atividades relacionam-se a gravação de vídeos a serem disponibilizados em Plataforma ou WhatsApp. O Projeto para a Educação Especial menciona, ainda, a equipe multidisciplinar e os cuidadores educacionais, designando as seguintes atividades: participação em reuniões e orientações aos familiares dos discentes.

Os planos e projetos apresentados e discutidos compõem as estratégias da SME de Floriano para implementar o ensino não presencial nesse período de pandemia, que requer como medida de saúde pública o isolamento social. A partir do mês de março foi iniciado o planejamento para organizar o ensino não presencial. Assim, os meses de março, abril e maio foram intensos nesse planejamento. Em sequência, as aulas foram retomadas em 15 de junho.

Para avaliar como estava sendo o acesso dos alunos e das alunas a SME elaborou um Relatório de acompanhamento das atividades pedagógicas no período de 15 de junho a 31 de julho. Segundo as informações contidas no relatório, o número de estudantes alcançados pelas aulas remotas da zona urbana no geral foi acima dos oitenta por cento, e apenas na modalidade de EJA que o número de discentes que foram alcançados pelo ensino não presencial se encontrava em torno de cinquenta e cinco por cento nos meses de junho e julho (FLORIANO, 2020e). 
MARTINS, Andreia; CAVALCANTI, Ágata Laisa Laremberg Alves; DOURADO, Anne Caroline Soares. Educar em tempos de incertezas: a implementação do ensino remoto na rede municipal de Floriano-Piauí

No relatório referente às escolas do Campo de Floriano, o número de estudantes alcançados pelas aulas remotas também foi muito bom, no geral ficando acima dos noventa por cento, incluindo a modalidade de educação de jovens e adultos. Ficamos em dúvidas sobre como esse levantamento foi realizado. O que significa os estudantes serem alcançados? Eles estão apenas recebendo as atividades, ou há um acompanhamento das aprendizagens destes alunos? Temos muitas questões que nos indicam a necessidade de novas investigações.

\section{Algumas considerações ...}

Buscamos tecer uma história do tempo presente e partido desse pressuposto metodológico não é possível qualquer conclusão. $\mathrm{O}$ estudo foi uma tentativa de entender como ocorreu o planejamento para a implementação das aulas não presenciais em Floriano. Verificamos que a SME, inicialmente, concedeu férias aos docentes e a equipe gestora começou a estudar e a planejar como ocorreria a transição das aulas presenciais para não presenciais, propondo como principais ferramentas a utilização do Whatsapp, Google classroom, Facebook e Instagram. Também deixaram explícito que fariam uso de cadernos, livros e atividades impressas, levadas aos estudantes que não tivessem acesso aos meios digitais.

Ao longo do texto, apresentamos e analisamos os documentos produzidos pela SME de Floriano para compreendermos como a equipe gestora concebeu o entendimento de como deveriam ser as aulas remotas e entendemos que foi proposto um amplo repertório de meios digitais e não digitais para alcançar os alunos da Educação infantil e do Ensino Fundamental. Do ponto de vista documental foi elaborada uma estratégia para o enfrentamento da pandemia e a vinculação dos estudantes ao conhecimento escolar.

Com base no relatório que apresenta o acompanhamento das crianças e dos adolescentes matriculados na Educação Infantil e no Ensino fundamental percebemos que há uma busca para alcançar os alunos em suas residências para que se envolvam com os ensinamentos escolares. É importante lembrarmos que estamos descrevendo uma cidade no semiárido piauiense, com sérios problemas de transporte público e acesso à conexão de internet. Então, fazem-se necessários novos estudos para entender como essas atividades chegavam e chegam aos alunos e como está sendo, na prática, o trabalho dos professores e das professoras.

Vivemos uma pandemia mundial, que nos mostrou uma crise nas instituições e, sobretudo, nas políticas públicas brasileiras. Podemos enxergar de forma escancarada as desigualdades de nosso país e a educação escolar - oriunda de uma cultura escolar presencial - se viu, da noite para o dia, em meio a um cenário cheio de incerteza. Buscamos entender, nesse texto, como o 
MARTINS, Andreia; CAVALCANTI, Ágata Laisa Laremberg Alves; DOURADO, Anne Caroline Soares. Educar em tempos de incertezas: a implementação do ensino remoto na rede municipal de Floriano-Piauí

município de Floriano-PI concebeu e construiu sua proposta de educação para o ensino remoto. Não é possível fazermos afirmativas referentes às vivências dos alunos e das alunas, dos docentes e dos gestores sobre esse período, pois estamos escrevendo uma história do tempo presente, onde a incerteza é nossa única certeza.

\footnotetext{
${ }^{1}$ https://cidades.ibge.gov.br/brasil/pi/floriano/panorama, acesso em 20/10/2020.
}

\section{Referências}

BAUMAN, Z. Modernidade Líquida. Tradução de Plínio Dentzien. Rio de Janeiro: Zahar, 2003.

BÉDARIDA, F. Tempo presente e presença da história. In: FERREIRA, Marieta de M.; AMADO, J. Usos e abusos da história oral. 5.ed. Rio de Janeiro: Ed. FGV, 2002.

BRASIL. Lei de Diretrizes e Bases da Educação Nacional. Lei número 9394, 20 de dezembro de 1996.

BURKE, P. (org.). A escrita da história: novas perspectivas. Tradução de Magda Lopes. São Paulo: UNESP, 1992.

GUIA COVID-19. Educaşão Especial na perspectiva inclusiva. Volume 7. São Paulo: Campanha Nacional pelo Direito à Educação, 2020.

DELGADO, L. de A. N.; FERREIRA, M. de M. História do tempo presente e ensino de História. Revista História Hoje, v. 2, n.4, p. 19-34 - 2013. Disponível em: https://rhhj.anpuh.org/RHHJ/article/view/90. Acesso em: 20 out. 2020.

FLORIANO. Decreto n. 032, de 16 de março de 2020. Regulamenta a Lei Federal no 13.979, de 06 de Fevereiro de 2020, bem como dispõe sobre as medidas temporárias a serem adotadas no âmbito do Município de Floriano para a prevenção e enfrentamento da emergência de saúde pública decorrente do novo coronavírus -COVID-19. Disponível em: http://floriano.pi.gov.br/download/202003/SF16_f18fbabf9a.pdf. Acesso em 19 out. 2020.

FLORIANO. Secretaria Municipal de Educação. Plano emergencial de orientações pedagógicas para o ensino não presencial na rede municipal de educação de Floriano Piauí. Floriano-PI, 2020b.

FLORIANO. Secretaria Municipal de Educação. Projeto Para Implementação de Atividades Não Presenciais na Modalidade de Educação de Jovens e Adultos (EJA) Durante a Pandemia de COVID-19. Floriano-PI, 2020c.

FLORIANO. Secretaria Municipal de Educação. Projeto Para Implementação de Atividades Não Presenciais na Modalidade de Educação Especial na perspectiva Inclusiva Durante a Pandemia de COVID-19. Floriano-PI, 2020d. 
MARTINS, Andreia; CAVALCANTI, Ágata Laisa Laremberg Alves; DOURADO, Anne Caroline Soares. Educar em tempos de incertezas: a implementação do ensino remoto na rede municipal de Floriano-Piauí

FLORIANO. Secretaria Municipal de Educação. Relatório de Acompanhamento das Atividades Pedagógicas no Período de 15 de Junho a 31 de Julho. Floriano-PI, 2020e.

JULIA, D. Cultura Escolar como Objeto Histórico. Revista Brasileira de História da Educação, v. 1, n. 1, p. 9-43, 16 fev. 2012. Disponível em: https://core.ac.uk/download/pdf/37742506.pdf . Acesso em 20 out. 2020.

MORAN, J. Contribuições para uma pedagogia da educação online. In.: SILVA, Marco. Educação online: teorias, práticas, legislação, formação corporativa. São Paulo: Loyola, 2003. p. 39-50.

MORIN, E. A cabeça bem-feita: repensar a reforma, reformar o pensamento. Tradução Eloá Jacobina. 8. ed. Rio de Janeiro: Bertrand Brasil, 2003.

PIAUÍ. Decreto n. 18.884, de 16 de março de 2020. Regulamenta a Lei no 13.979 , de 06 de fevereiro de 2020, para dispor no âmbito do Estado do Piaú, sobre as medidas de emergência de saúde pública de importância internacional e tendo em vista a classificação da situação mundial do novo coronavírus como pandemia, institui o Comitê de Gestão de Crise, e dá outras providências. Governo de Estado do Piauí, 2020. Disponível em: https://www.pi.gov.br/wpcontent/uploads/2020/03/Decreto-18.884-de-16-03-2020.pdf. Disponível em: https://www.pi.gov.br/wp-content/uploads/2020/03/Decreto-18.884-de-16-03-2020.pdf. Acesso em: 19 out. 2020.

PRETTO, Nelson; BONILLA, Maria Helena; SENA, Ivânia. Educação em tempos de pandemia: reflexões sobre as implicações do isolamento físico imposto pela COVID-19. Salvador: Edição do Autor, 2020.

SANTANA, C. L. S.; BORGES, S. K. M. Aula em casa: educação, tecnologias digitais e pandemia COVID-19. Interfaces Científicas - Educação, v.10, n.1, p.75-92, 2020. Disponível em: https://periodicos.set.edu.br/educacao/article/view/9181/4130. Acesso em: 28 out. 2020.

Recebido em: 30 out. 2020/ Aprovado em: 01 dez. 2020

\section{Cite como}

(ABNT NBR 6023:2018)

MARTINS, Andreia; CAVALCANTI, Ágata Laisa Laremberg Alves; DOURADO, Anne Caroline Soares. Educar em tempos de incertezas: a implementação do ensino remoto na rede municipal de Floriano-Piauí. Dialogia, São Paulo, n. 36, p. 73-85, set./dez. 2020. Disponível em: https://doi.org/10.5585/dialogia.n36.18619.

\section{American Psychological Association (APA)}

Martins, A., Cavalcanti, Á. L. L. A., \& Dourado, A. C. S. (2020, set./dez.). Educar em tempos de incertezas: a implementação do ensino remoto na rede municipal de Floriano-Piauí. Dialogia, São Paulo, 36, p. 73-85. https://doi.org/10.5585/dialogia.n36.18619. 